\title{
Dual-foraging of Cory's shearwaters in the Azores: feeding locations, behaviour at sea and implications for food provisioning of chicks
}

\author{
M. C. Magalhães ${ }^{1,2, *}$, R. S. Santos ${ }^{2}$, K. C. Hamer ${ }^{1}$ \\ ${ }^{1}$ Faculty of Biological Sciences and Earth Biosphere Institute, University of Leeds, Leeds LS2 9JT, UK \\ ${ }^{2}$ Department of Oceanography and Fisheries, University of the Azores, 9901-862 Horta, Faial, Portugal
}

\begin{abstract}
Many procellariiform (tube-nosed) seabirds employ a dual-foraging strategy involving repeated alternation of short and long foraging trips. For species breeding at sites around the Southern Ocean, long trips typically extend to areas of enhanced productivity at great distance from the nest. Evidence concerning the use of such areas during dual-foraging in other oceanographic regions is, however, limited. The present study examines the foraging strategy, locations and behaviour at sea of Cory's shearwaters in the Azores, a chain of 9 islands and associated islets in 3 groups straddling the mid-Atlantic ridge (MAR) in the North Atlantic Ocean. Adults used a dual-foraging strategy with an average of 3 short ( 1 to $4 \mathrm{~d}$ ) trips followed by a long trip of up to $20 \mathrm{~d}$ (average $9 \mathrm{~d}$ ). Short trips were evenly distributed around breeding sites within an average range of $75 \mathrm{~km}$, whereas long trips without exception headed north of the Azores and extended up to $1800 \mathrm{~km}$ from the nest. Core foraging areas for long trips were within apparent regions of enhanced productivity resulting from cold water upwelling along the MAR north of the colony (for birds from the central Azores) or over the western flank of the MAR northwest of the colony (for birds from the western Azores). On long trips from all 3 island groups birds also visited an additional area of enhanced productivity in the region of Flemish Cap, close to the North American continental shelf edge. Birds commuted to and from distant foraging sites relatively quickly $\left(25 \mathrm{~km} \mathrm{~h}^{-1}\right.$ on average), but individual parents did not co-ordinate their foraging activity to reduce the frequency of nights when chicks were unfed. As a result, chicks experienced much longer intervals between feeds (up to 9 nights) than conspecifics at other North Atlantic islands in the absence of dual-foraging (maximum 4 nights). However, chicks in the Azores received much larger meals when they were fed, and so the overall food provisioning rate $\left(\mathrm{g} \mathrm{d}^{-1}\right)$ was similar to that recorded elsewhere.
\end{abstract}

KEY WORDS: Calonectris diomedea $\cdot$ Wildlife telemetry $\cdot$ Seamounts $\cdot$ Geolocation $\cdot$ Home range Optimal foraging

Resale or republication not permitted without written consent of the publisher

\section{INTRODUCTION}

During the breeding season, foraging behaviour forms an essential link between prey availability and predator reproductive success. Flexibility in foraging behaviour may be particularly important when the distribution and abundance of prey is variable or when parents need to travel long distances to access prey resources (Wilson et al. 2005, Hamer et al. 2007). Pelagic seabirds routinely travel long dis- tances from the nest, making foraging trips of several hours to several days duration and travelling tens to thousands of kilometres from the breeding site on a single trip (Hedd \& Gales 2005, Phillips et al. 2005). Advances in remote-sensing technology have provided increasingly detailed information on the foraging locations and behaviour of pelagic seabirds (see Weimerskirch 2007 for recent review) but there is still relatively little information on how distances travelled and behaviour during foraging trips vary in 
relation to trip duration under different environmental conditions or in relation to parental foraging strategies.

Recent studies have shown that many procellariiform (tube-nosed) seabirds employ a dual or bimodal foraging strategy that alternates short foraging trips, used mainly to procure food for the chick, with trips of longer duration during which parents replenish their own nutritional reserves depleted during short trips (Weimerskirch et al. 1994, Stahl \& Sagar 2000, Terauds $\&$ Gales 2006). For species breeding at sites around the Southern Ocean, long trips typically extend to areas of enhanced productivity associated with continental shelves, shelf slopes or frontal zones at great distance from the nest, in particular the Antarctic Polar Frontal Zone, more than $2000 \mathrm{~km}$ from many breeding colonies (Waugh et al. 1999, Catard et al. 2000, Klomp \& Schultz 2000). Evidence concerning the use of such areas of enhanced productivity in other oceanographic regions is, however, limited (Hyrenbach et al. 2002). Adults could remain close to the colony but take prey solely for their own use during trips of long duration rather than visiting distant sites (Ropert-Coudert et al. 2004, Congdon et al. 2005), and there is very little information concerning destinations of long trips for regions other than the Southern Ocean (Weimerskirch et al. 2001, Hamer et al. 2006). Indeed, little is known about the prevalence of dual-foraging among Procellariiformes in other regions (see Baduini \& Hyrenbach 2003 for recent review).

In the northern hemisphere, Laysan albatrosses Phoebastria immutabilis and black-footed albatrosses $P$. nigripes nesting in the Hawaiian Islands employ bimodal foraging-trip strategies, with long trips visiting productive regions associated with frontal zones in colder waters and at higher latitudes (Fernandez et al. 2001, Hyrenbach et al. 2002). However, wedge-tailed shearwaters Puffinus pacificus at the same site do not use a dual-foraging strategy and appear to forage mainly in waters close to the colony (Baduini 2002), which casts doubt on whether the findings for albatrosses have general validity for other Procellariiformes. Moreover, whilst wedge-tailed shearwaters do exhibit dual-foraging in NE Australia (Congdon et al. 2005), it is not known whether or not foraging ranges differ between short and long trips in that region.

In the North Atlantic Ocean, there is little evidence of bimodal foraging trips and the marine environments exploited by Procellariiformes are only poorly understood (Mougin \& Jouanin 1997, Gray \& Hamer 2001, Weimerskirch et al. 2001). Cory's shearwaters Calonectris diomedea in the sub-tropical North Atlantic exhibited dual-foraging under conditions of low food availability around the colony in 1997 (Granadeiro et al. 1998a) but not in other years or at other sites with higher chick-feeding rates (Granadeiro et al. 1998a, Hamer et al. 1999) and the foraging ranges and locations of adults during chick-rearing were again unknown. Thus, further data are needed, particularly for species other than albatrosses, to determine the prevalence of dual-foraging and the locations and behaviour of birds on trips of different duration in oceanographic regions beyond the Southern Ocean.

Large populations of Cory's shearwaters (50000 to 90000 pairs, comprising $>70 \%$ of breeding numbers of the Atlantic subspecies Calonectris diomedea borealis; Monteiro et al. 1996) breed in the Azores, a chain of 9 islands and associated islets in 3 groups straddling the mid-Atlantic ridge (MAR) over a distance of about $600 \mathrm{~km}$ (see Fig. 1). Marine transects along the MAR have recorded adults of this species foraging in association with dolphin species over $1000 \mathrm{~km}$ north of the Azores during the breeding season (Nøttestad \& Olsen 2005) and this raises the possibility that adults breeding in the Azores may employ dual-foraging to exploit prey resources in such distant locations. Cory's shearwaters are opportunistic predators, and diets of adults in the eastern Azores differ markedly from those in the central and western islands during chick-rearing (Granadeiro et al. 1998b). However, it is not known to what extent this pattern reflects variation in the marine environments utilized by adults. The present study examines the foraging strategy, locations and behaviour at sea of Cory's shearwaters in the Azores. We test the hypothesis that adults employ dual-foraging to exploit productive regions in waters north of the archipelago and examine how foraging locations and behaviour vary between island groups. Dual-foraging, which involves making both short and long trips, could result in longer average intervals between feeds and lower overall feeding rates of chicks $\left(\mathrm{g} \mathrm{d}^{-1}\right)$ compared to unimodal foraging, but there are few data within individual species to address this issue (Granadeiro et al. 1998a, Terauds \& Gales 2006). Hence we also assess the impact of variation in foraging strategy on the food provisioning rates of chicks.

\section{MATERIALS AND METHODS}

Species and study sites. Cory's shearwaters breed throughout the Azores Islands, and the present study was conducted at 3 sites spanning the archipelago (Fig. 1): Corvo Island in the western group $\left(40^{\circ} \mathrm{N}\right.$, $\left.31^{\circ} \mathrm{W}\right)$, Praia Islet near Graciosa in the central group $\left(39^{\circ} \mathrm{N}, 28^{\circ} \mathrm{W}\right)$ and Vila Islet near Santa Maria in the eastern group $\left(37^{\circ} \mathrm{N}, 25^{\circ} \mathrm{W}\right)$. Adults in the Azores nest in burrows and lay a single egg, which typically hatches in mid- to late July. Chicks are fed nocturnally 


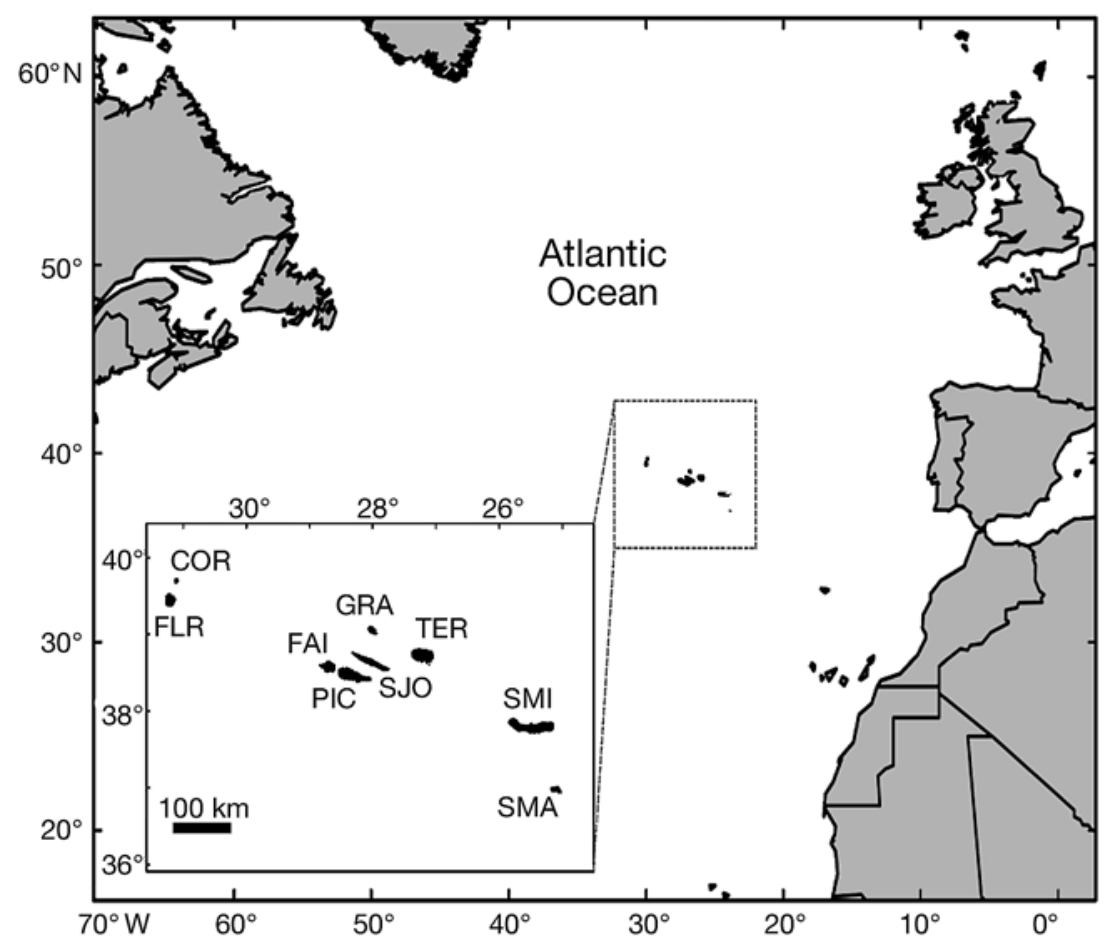

Fig. 1. North Atlantic Ocean showing position of Azores archipelago. Inset shows individual islands. Western Group: $\mathrm{COR}=\mathrm{Corvo}, \mathrm{FLR}=$ Flores; Central Group: GRA $=$ Graciosa, FAI $=$ Faial, PIC $=$ Pico, SJO $=$ São Jorge, TER $=$ Ter ceira; Eastern Group: SMI = São Miguel, SMA = Santa Maria. Study sites were at Corvo and islets offshore from Graciosa and Santa Maria transmitter (PTT; Microwave Telemetry) weighing $30 \mathrm{~g}(<4 \%$ of adult mass $)$ and with a duty-cycle of continuous transmission was attached to 23 birds ( $\mathrm{n}=8$ in the western Azores in 2004, 5 in the eastern Azores in 2005, and 10 in the central Azores in 2006) in the same way as for radio-transmitters. A blood sample (less than $0.1 \mathrm{ml}$ ) was also taken under licence from the tarsal vein of each bird for DNA sexing following Fridolfsson \& Ellegren (1999). Attachment of tags and bloodsampling took <15 min and birds were then returned immediately to the nest.

Trip durations and foraging behaviour at sea. After release, visits of radiotagged birds to the colony were recorded for a mean of $44 \mathrm{~d}(\mathrm{SD} \pm 25)$ during chickrearing each year, using an ATS R4500 scanning receiver attached to an ATS omni-directional antenna located at the colony. Field trials indicated that the range of this system was ca. $1 \mathrm{~km}$, so we were confident that signals received were from birds in the vicinity of their nests and not at sea. Birds carrying PTTs were tracked for a mean of $17 \mathrm{~d}(\mathrm{SD} \pm 5)$ over a period of 38 to $44 \mathrm{~d}$ during chick-rearing each year. A recent review of effects of transmitters indicated negligible adverse by both parents for about $90 \mathrm{~d}$ before fledging in midto late October. Chicks are fed small meals relatively frequently ( $>95 \%$ of chicks fed each night) for the first $10 \mathrm{~d}$ post-hatching and are fed infrequently $(<25 \%$ of chicks fed each night) prior to fledging, but both meal size and feeding frequency are more or less independent of chick age over the range 10 to $70 \mathrm{~d}$ (Hamer \& Hill 1993, Ramos et al. 2003).

Field protocol. Fieldwork took place from late July to mid-September 2004 to 2006, and all data were for nests with chicks aged 10 to $60 \mathrm{~d}$ (chick ages determined shortly after hatching by calibration of wing-length against growth in birds of known age; Granadeiro 1991). Over the 3 yr of the study, 82 adults were captured at night by hand at nests with hatching dates $\pm 2 \mathrm{wk}$ from the annual mode $(\mathrm{n}=18$ birds in the western Azores plus 19 birds in the eastern Azores in 2004, 35 in the eastern Azores in 2005, and 10 in the central Azores in 2006). A VHF radio-transmitter (ATS in 2004; Biotrack in 2005) weighing 15 and $10 \mathrm{~g}$, respectively $(<2 \%$ of body mass in each case) was attached to the back feathers of 59 birds ( $n=10$ in the western Azores plus 19 birds in the eastern Azores in 2004, and 30 in the eastern Azores in 2005) using waterproof tape (Tesa). In addition, a platform terminal effects for tags weighing up to $3 \%$ of adult body mass (Phillips et al. 2003), and for Cory's shearwaters, 12 to $15 \mathrm{~g}$ data loggers and radio-transmitters had no discernible impacts on foraging, nest attendance or food delivery to chicks (Hamer et al. 1999, Igual et al. 2005). In addition, there was no significant difference in our study between foraging trip durations of birds carrying radio-transmitters $(2.8 \pm 3.7 \mathrm{~d}, \mathrm{n}=940)$ and those carrying PTTs $(3.2 \pm 3.9 \mathrm{~d}, \mathrm{n}=100$; generalized linear model, GLM, including island and trip type [long or short; see 'Results'] as fixed effects, and bird identity nested within island as a random effect; $F_{1,985}=0.1, \mathrm{p}=$ 0.7 ). Data were collected over a period of $3 \mathrm{yr}$ but there was no difference between trip durations of birds in the eastern Azores in 2004 and 2005 (GLM; $F_{1,189.7}=$ 1.9, $\mathrm{p}=0.2$ ), suggesting that foraging behaviour did not vary from year to year.

Data provided by PTTs were processed using the Advanced Research and Global Observation Satellite (ARGOS) facility in France (Centre National d'Etudes Spatiales, CNES). Following previous authors (e.g. Hedd et al. 2001, Hamer et al. 2007), we used only data of Class A or better (average of 13.3 locations bird ${ }^{-1}$ $\mathrm{d}^{-1}$ ) to examine foraging locations at sea, giving us a maximum SD on each location of $<10 \mathrm{~km}$, which was 
small in comparison to distances travelled by birds (see Table 1). Locations of birds at sea were examined in Arc-View GIS and the scale of movements each year was compared using fixed kernel density (FKD) estimates with least-squares cross-validation (Worton 1989, Beisiegel \& Mantovani 2006). Following previous authors (e.g. Iversen \& Esler 2006, Hamer et al. 2007) we considered the $95 \%$ and $50 \%$ FKD estimates to represent the area of active use and the core area of foraging activity, respectively.

To examine individual foraging trips in more detail, we used the furthest recorded location from the colony during each trip to provide information on trip destinations and we also calculated total distance travelled as the sum of distances between consecutive locations at sea. The average speed of travel during trips was then calculated as (total distance/duration), and the directness of travel was estimated by calculating the maximum range as a percentage of the total distance travelled.

In order to examine movements over shorter intervals within the total foraging ranges of birds, we estimated travel speeds during short sections of each trip as the distance between consecutive pairs of locations divided by the time elapsed between them. The time between locations influenced the estimated speeds of travel, with increasing underestimates resulting from locations spaced further apart $\left(F_{4,4451}=\right.$ 64.4, $\mathrm{p}<0.001)$. Specifically, estimates from locations separated by $\leq 2 \mathrm{~h}\left(21.7 \pm 19.2 \mathrm{~km} \mathrm{~h}^{-1}, \mathrm{n}=3547\right)$ were significantly greater than those at all longer temporal resolutions $\left(2-4 \mathrm{~h}, 12.1 \pm 4.0 \mathrm{~km} \mathrm{~h}^{-1}, \mathrm{n}=707 ; 4-6 \mathrm{~h}\right.$, $7.8 \pm 4.1 \mathrm{~km} \mathrm{~h}^{-1}, \mathrm{n}=137 ; 6-8 \mathrm{~h}, 7.3 \pm 4.6 \mathrm{~km} \mathrm{~h}^{-1}, \mathrm{n}=33$; $8-10 \mathrm{~h}, 7.8 \pm 4.8 \mathrm{~km} \mathrm{~h}^{-1}, \mathrm{n}=32$; Tukey's HSD, $\mathrm{p}<0.01$ ). We therefore limited further analysis of travel speeds to locations spaced by $\leq 2 \mathrm{~h}(\mathrm{n}=3547)$.

Food delivery to the nest. Parental food provisioning can be partitioned into the probability that a chick is fed overnight (derived from feeding frequency) and the mass of food delivered when fed (here termed feed size). To quantify feed sizes and feeding frequencies of chicks at each island, a sample of chicks aged 10 to $60 \mathrm{~d}$ ( $\mathrm{n}=14$ in the western, 17 in the central, and 46 in the eastern Azores) was weighed to the nearest $5 \mathrm{~g}$ using a Pesola spring balance at 20:00 h (before the first parents returned overnight) each day from 29 July to 6 September 2004 (39 d) in the western Azores, from 3 August to 17 September 2006 (45 d) in the central Azores and from 4 August to 7 September 2005 (34 d) in the eastern Azores (range of ages: western Azores, 10-52 d, mean = 29.2 $\pm 11.2 \mathrm{~d}$; central Azores, 10-59 d, mean $=32.9 \pm 13.5 \mathrm{~d}$; eastern Azores, 10-50 d, mean = $26.5 \pm 9.7 \mathrm{~d}$ ). Chicks were also weighed at 01:00 $\mathrm{h}$ and 06:00 h (after the last parents had departed each morning) on up to 10 nights at each colony. Feed size was calculated from the sum of positive mass increments recorded overnight, using equations in Hamer et al. (1999) to correct for the mass lost through digestion, respiration and excretion between weighings. Feeding frequency was then estimated from net daily mass changes calibrated against overnight feeding, following Hamer \& Hill (1997).

Data analysis. In many cases we recorded more than 1 foraging trip per bird. To examine individual variation in foraging and food provisioning behaviour and to take account of potential pseudoreplication of data, we therefore used generalized linear models (GLMs), or generalized linear mixed models (GLMMs) for nonnormal data, with island included as a fixed effect and bird identity included as a random effect nested within island. Means are given $\pm 1 \mathrm{SD}$ unless otherwise stated.

\section{RESULTS}

\section{Foraging trip durations and time spent foraging}

We recorded the duration of 1040 trips of 82 birds at 3 colonies (134 trips of 18 birds in the western Azores in $2004 ; 855$ trips of 54 birds in the eastern Azores in 2004 and 2005; 51 trips of 10 birds in the central Azores in 2006). Trips lasted up to $20 \mathrm{~d}$ but the majority of trips (71\%) were a single day (Fig. 2). The frequency distribution of trip durations was bimodal with 2 separate peaks in abundance at durations of $1 \mathrm{~d}$ and $10 \mathrm{~d}$ (Fig. 2a), indicating a clear separation between short and long trips. The proportion of time at sea spent on trips of different duration showed a similar pattern, with trips lasting 4 to $5 \mathrm{~d}$ being less frequent and taking up less of the birds' time than either shorter or longer trips (Fig. 2b). Classifying trips of 1 to $4 \mathrm{~d}$ as short trips (ST) and those of $\geq 5 \mathrm{~d}$ as long trips (LT), birds spent $35.5 \pm 16.3 \%$ of their time on STs (mean duration $=1.1 \pm 0.4 \mathrm{~d}, \mathrm{n}=836)$ and $64.5 \pm 16.3 \%$ of their time on LTs (mean $=9.8 \pm 3.1 \mathrm{~d}, \mathrm{n}=204$ ), with no difference between islands in the distribution of STs and LTs (Fig. 2c). Each bird visited the nest on $36.7 \pm 15.4 \%$ of nights (Table 1 ) with no difference in this proportion among islands or between males and females (analysis of variance using arcsine-transformed data; $F_{2,71}=0.7, \mathrm{p}=0.5$ and $F_{1,71}=0.02, \mathrm{p}=0.9$, respectively). On average, each bird made 3 STs between consecutive LTs (mean $=2.98 \pm 2.7, \mathrm{n}=124$, range $=0$ to 12 ), with the duration of LTs significantly positively related to the number of consecutive preceding STs $\left(\mathrm{GLM} ; F_{1,77}=6.5, \mathrm{p}=0.01\right)$. There was no difference in the slope or elevation of this relationship among islands, between males and females or among birds at each island ( $p>0.1$ in all cases). 


\section{Foraging locations}

The maximum distance of STs was $588 \mathrm{~km}$ from the colony in the western Azores, $214 \mathrm{~km}$ in the central Azores and $107 \mathrm{~km}$ in the eastern Azores (Fig. 3). The duration of STs from the western Azores were more than $50 \%$ longer on average than those from the other island groups (Table 1; GLMM; $\chi^{2}{ }_{2}=14.3, \mathrm{p}<0.01$ ), maximum range $\left(G L M ; F_{2,21.2}=4.5, \mathrm{p}<0.05\right)$ and total distance travelled $\left(\mathrm{F}_{2,20.4}=3.7, \mathrm{p}<0.05\right)$, with no significant difference between males and females or among birds at each island ( $p>0.5$ in each case). Destinations of STs were mainly over the MAR and were widely spaced, with a similar frequency of trips north and south at all 3 islands (Fig. 3; western Azores, 7 north, 12 south, $\chi_{1}^{2}=0.7, \mathrm{p}=$ 0.5; central Azores, 29 north, 12 south, $\chi_{1}{ }^{2}=3.7, \mathrm{p}=0.1$; eastern Azores, 10 north, 5 south, $\chi_{1}^{2}=0.9, \mathrm{p}=0.5$ ).

In the central and eastern Azores, trips north and south were similar in terms of duration, range and distance travelled ( $p>0.1$ in all cases). In the western Azores, however, trips north were much longer than trips south in terms of duration $(2.1 \pm 0.9 \mathrm{~d}$ and $1.1 \pm 0.3 \mathrm{~d}$, respectively; $\left.F_{1,13.3}=10.7, \mathrm{p}<0.01\right)$, maximum range $(270.3 \pm$ $214.1 \mathrm{~km}$ and $38.6 \pm 28.3 \mathrm{~km}$, respectively; $F_{1,14.9}=10.2$, $\mathrm{p}<0.01)$ and total distance travelled $(711.4 \pm 502.6 \mathrm{~km}$ and $186.7 \pm 106.1 \mathrm{~km}$ respectively; $\left.F_{1,14.4}=8.5, \mathrm{p}=0.01\right)$. This was because trips south mainly stayed close to the coasts of Corvo and Flores (the 2 western islands; Figs. 1 \& 3), whereas some trips north headed across deep water (>3000 m) west of the MAR (Fig. 3). FKD estimates indicated that the area used for foraging (95\% FKD) was largest in the western Azores; 5.2 times larger than in the central Azores and 9.4 times larger than in the eastern Azores (Table 1), with no overlap between islands in areas used (Fig. 3). The core foraging area (50\% FKD) was also largest in the western Azores; 4.7 times larger than in the central Azores and 9.2 times larger than in the eastern Azores. Despite these differences between islands in terms of distances travelled on STs, the core foraging area was a similar proportion of the total area used in each case $(14.0 \%$ in the western, $15.4 \%$ in the central Azores, and $14.3 \%$ in the eastern Azores; calculated from data in Table 1).

LTs without exception headed north of the Azores, to a maximum range of $1315 \mathrm{~km}$ for birds nesting in the western Azores, $1528 \mathrm{~km}$ for the central Azores and $1819 \mathrm{~km}$ for the eastern Azores (Fig. 4). Trips from the central Azores almost all headed along the MAR, with maximum ranges mainly at 45 to $48^{\circ} \mathrm{N}$ but with some trips extending as far as the Charlie Gibbs Fracture Zone at $52^{\circ} \mathrm{N}$ (Fig. 4). Trips from the western Azores nearly all headed NW of the colony, with maximum ranges mostly along the western edge of the MAR but with some trips heading across deeper water (>3000 m; Fig. 4). Foraging tracks of birds from the
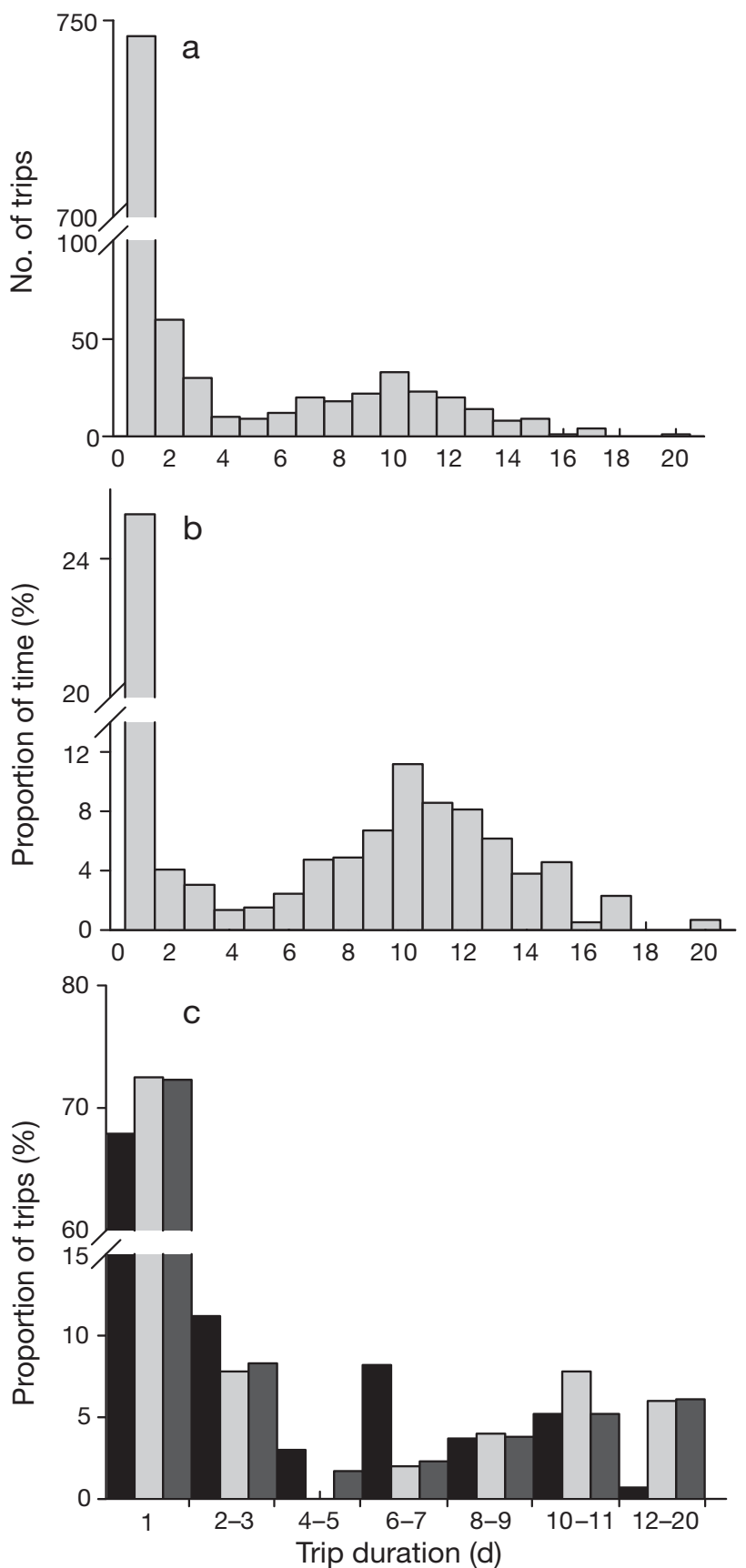

Fig. 2. Calonectris diomedea. (a) Durations of foraging trips by adults raising chicks at colonies in the Azores; (b) proportion of time spent on trips of different durations; (c) proportions of trips of different durations in the western Azores (black), central Azores (light grey) and eastern Azores (dark grey)

eastern Azores were more variable, with destinations both east and west of the MAR, from 15 to $44^{\circ} \mathrm{W}$. At least 1 LT from each island took birds close to the North American continental shelf east of Newfoundland at Flemish Cap (Fig. 4). There was extensive overlap in the foraging paths and total foraging areas (95\% FKDs) of birds from different islands, both along the MAR and 
Table 1. Calonectris diomedea. Characteristics of foraging trips made by adults rearing chicks at different islands in the Azores. Attendance at nest and trip durations based on 134 trips (106 short, 28 long) of 18 birds in the western Azores; 51 trips (41 short, 10 long) of 10 birds in the central Azores; 855 trips (689 short, 166 long) of 54 birds in the eastern Azores. All other data from satellite telemetry of 30 trips (19 short, 11 long) of 8 birds in the western Azores, 51 trips (41 short, 10 long) of 10 birds in the central Azores, 19 trips (15 short, 4 long) of 5 birds in the eastern Azores. FKD: fixed kernel density

\begin{tabular}{|c|c|c|c|c|c|c|c|c|c|c|c|c|c|c|}
\hline \multirow{2}{*}{$\begin{array}{l}\text { Island } \\
\text { group } \\
\text { and trip }\end{array}$} & \multirow{2}{*}{\multicolumn{2}{|c|}{$\begin{array}{l}\text { Prop. nights } \\
\text { birds at nest } \\
\text { Mean SD }\end{array}$}} & \multicolumn{2}{|c|}{$\begin{array}{c}\text { Trip } \\
\text { duration (d) }\end{array}$} & \multicolumn{2}{|c|}{$\begin{array}{c}\text { Max. } \\
\text { distance }(\mathrm{km})\end{array}$} & \multicolumn{2}{|c|}{$\begin{array}{c}\text { Total } \\
\text { distance }(\mathrm{km})\end{array}$} & \multirow{2}{*}{$\begin{array}{l}95 \% \\
\text { FKD } \\
\left(\mathrm{km}^{2}\right)\end{array}$} & \multirow{2}{*}{$\begin{array}{l}50 \% \\
\text { FKD } \\
\left(\mathrm{km}^{2}\right)\end{array}$} & \multicolumn{2}{|c|}{$\begin{array}{c}\text { Speed }^{\mathrm{a}} \\
\left(\mathrm{km} \mathrm{d}^{-1}\right)\end{array}$} & \multicolumn{2}{|c|}{$\begin{array}{l}\text { Speed }^{\mathrm{b}} \\
\left(\mathrm{km} \mathrm{d}^{-1}\right)\end{array}$} \\
\hline & & & Mean & $\mathrm{SD}$ & Mean & $\mathrm{SD}$ & Mean & $\mathrm{SD}$ & & & Mean & $\mathrm{SD}$ & Mean & $\mathrm{SD}$ \\
\hline Western & 0.34 & 0.14 & & & & & & & & & & & & \\
\hline Short & & & 1.53 & 0.80 & 133.7 & 177.7 & 406.2 & 413.9 & 15922 & 2226 & 125.0 & 48.5 & 222.6 & 58.8 \\
\hline Long & & & 7.09 & 1.92 & 758.4 & 294.2 & 2487.3 & 926.7 & 562457 & 57654 & 214.4 & 56.7 & 348.9 & 72.1 \\
\hline Central & 0.33 & 0.18 & & & & & & & & & & & & \\
\hline Short & & & 1.15 & 0.48 & 55.9 & 41.3 & 230.2 & 160.4 & 3039 & 469 & 86.0 & 38.5 & 193.5 & 69.7 \\
\hline Long & & & 10.60 & 2.68 & 1233.5 & 204.6 & 4209.5 & 481.9 & 778266 & 73029 & 241.4 & 81.7 & 409.0 & 99.7 \\
\hline Eastern & 0.38 & 0.15 & & & & & & & & & & & & \\
\hline Short & & & 1.07 & 0.27 & 54.4 & 31.9 & 234.7 & 120.3 & 1690 & 242 & 99.1 & 38.1 & 206.4 & 62.3 \\
\hline Long & & & 9.76 & 3.56 & 1570.3 & 220.6 & 5573.8 & 827.1 & 1286950 & 94172 & 209.5 & 19.5 & 371.2 & 33.6 \\
\hline
\end{tabular}

in the vicinity of the North American continental shelf. However the core foraging areas (50\% FKDs) were widely separated and non-overlapping (Fig. 5).

Together with differences in core foraging areas, LTs from the western Azores were 40 to $50 \%$ shorter on average than those elsewhere in terms of duration (Table 1; GLM; $F_{2,20.6}=18.3, \mathrm{p}<0.001$ ) maximum range from the colony $\left(F_{2,19.7}=15.5, \mathrm{p}<0.001\right)$ and total distance travelled $\left(F_{2,20.2}=24.9, \mathrm{p}<0.001\right)$, with no significant difference between sexes or among birds at each island ( $p>0.3$ in each case). The area used for foraging (95\% FKD) in the western Azores was 0.72 times that in the central Azores and 0.44 times that in the eastern Azores, whilst the core foraging area (50\% FKD) was 0.79 times that in the central Azores and 0.61 times that in the eastern Azores (Fig. 5). As with STs, the core foraging area was a similar proportion of the total area used around each island $(10.3 \%$ in the western, $9.4 \%$ in the central, and $7.3 \%$ in the eastern Azores; from data in Table 1). The total area encompassed by STs and LTs from all 3 islands was ca 1.8 million $\mathrm{km}^{2}$ (Figs. 3 \& 4).

\section{Average speeds of travel over complete trips}

Across all foraging trips, there was a positive linear relationship between trip duration and both maximum range from the colony (GLM excluding intercept; $\left.F_{1,73}=33.6, \mathrm{p}<0.001, \mathrm{R}^{2}=0.93\right)$ and total distance travelled $\left(F_{1,73}=48.2, \mathrm{p}<0.001, \mathrm{R}^{2}=0.96\right)$. The slopes of these relationships were significantly higher for LTs than for STs (for maximum range, $F_{1,73}=4.7, \mathrm{p}<0.05$; for total distance travelled, $F_{1,73}=7.8, \mathrm{p}<0.01$ ), indicating a higher rate of travel during LTs, according to the following relationships for STs:

$$
\begin{gathered}
\text { Maximum distance }(\mathrm{km})= \\
69.5(\mathrm{SE} \pm 6.8) \text { trip duration }(\mathrm{d}) \\
\text { Total distance }(\mathrm{km})= \\
232.0(\mathrm{SE} \pm 17.1) \text { trip duration }(\mathrm{d})
\end{gathered}
$$

and for LTs:

$$
\begin{gathered}
\text { Maximum distance }(\mathrm{km})= \\
\text { 107.6 }(\mathrm{SE} \pm 5.1) \text { trip duration }(\mathrm{d}) \\
\text { Total distance }(\mathrm{km})= \\
371.8(\mathrm{SE} \pm 13.1) \text { trip duration }(\mathrm{d})
\end{gathered}
$$

Average speed during these trips was thus estimated as $139(\mathrm{SE} \pm 14) \mathrm{km} \mathrm{d}^{-1}$ during STs and $215(\mathrm{SE} \pm 10) \mathrm{km}$ $\mathrm{d}^{-1}$ during LTs (twice the slope of Eqs. 1 and 3, respectively) using maximum range from the colony, and as $232(\mathrm{SE} \pm 17) \mathrm{km} \mathrm{day}^{-1}$ during STs and $372(\mathrm{SE} \pm 13) \mathrm{km}$ day $^{-1}$ during LTs (the slopes of Eqs. 2 and 4, respectively) using total distance travelled. GLMs indicated no difference between islands in the slopes of these relationships ( $p>0.1$ in both cases) and this was confirmed by comparison among islands of the mean travel speeds for individual birds (Table 1; 1-way ANOVA using a single value for each bird; from maximum range from the colony, $F_{2,15}=1.6, \mathrm{p}=0.2$ and $F_{2,18}=0.5, \mathrm{p}=0.6$ for ST and LT, respectively; from total distance travelled, $F_{2,15}=0.4, \mathrm{p}=0.7$ and $F_{2,18}=1.2, \mathrm{p}=0.3$ for ST and $L T$, respectively). The maximum range comprised $29.6 \pm 3.5 \%(n=25)$ of the total distance travelled during LTs, significantly more than during STs (25.0 \pm 9.9\% ( $\mathrm{n}=75$; GLM using arcsine-transformed data; $\left.F_{1,74}=10.5, \mathrm{p}=0.002\right)$, suggesting that birds travelled to foraging areas and back more directly during LTs. Directness of travel also varied significantly among individuals at each island $\left(F_{19,74}=3.0, \mathrm{p}<0.001\right)$ but did not differ between islands $\left(F_{2,26.5}=0.2, \mathrm{p}=0.8\right)$. 

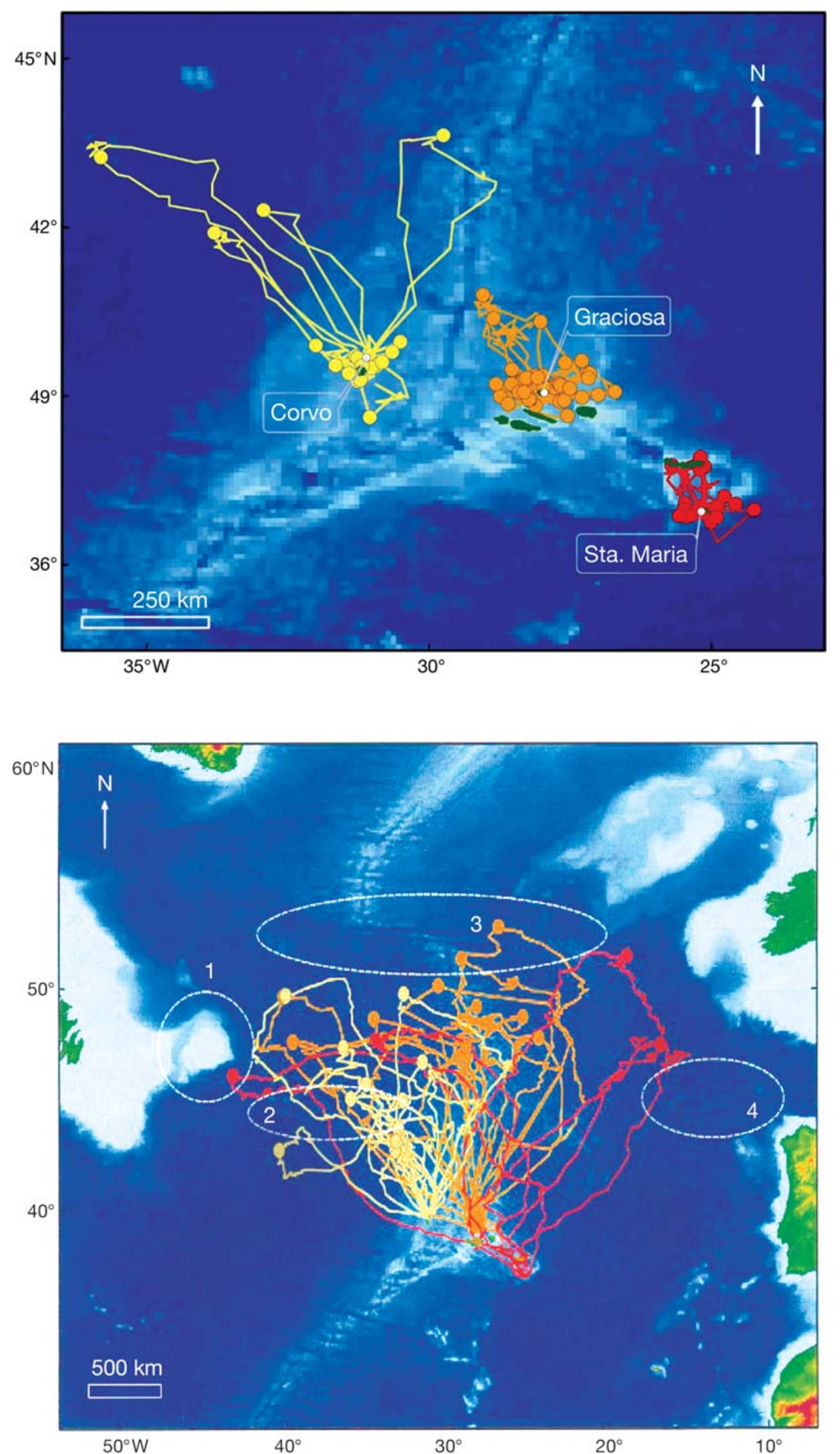

Fig. 3. Calonectris diomedea. Foraging ranges and destinations of short trips (1 to $4 \mathrm{~d}$ ) from 3 islands in the western (yellow), central (orange) and eastern (red) Azores. Circles mark maximum ranges for individual foraging trips. Palest blue indicates depths below $1000 \mathrm{~m}$ and darkest blue depths above $3000 \mathrm{~m}$
Fig. 4. Calonectris diomedea. Foraging ranges and destinations of long trips (5 to $18 \mathrm{~d}$ ) from 3 islands in the western (yellow), central (orange) and eastern (red) Azores. Circles mark maximum ranges for individual foraging trips. Oceanographic features: $1=$ Flemish Cap; 2 = Milne seamounts; $3=$ Charlie Gibbs Fracture Zone; $4=$ Charcot seamounts. Palest blue indicates depths below $1000 \mathrm{~m}$ and darkest blue depths above $3000 \mathrm{~m}$ 


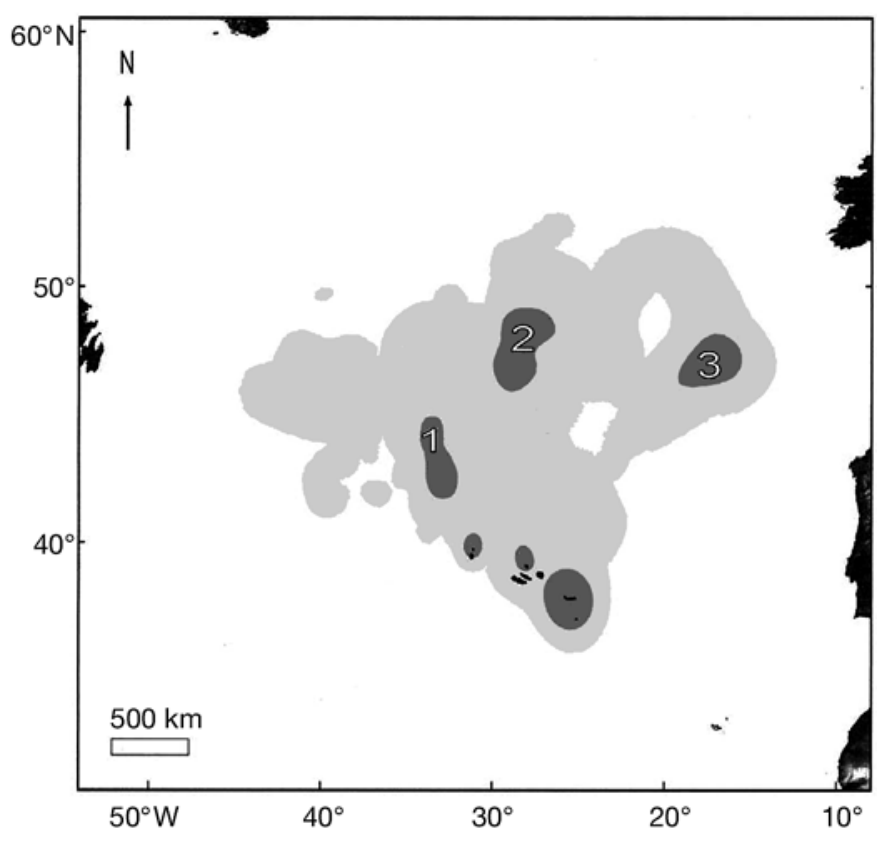

Fig. 5. Calonectris diomedea. Kernels encompassing 50\% (dark grey) and 95\% (light grey) of locations at sea during long trips from 3 islands in the Azores. Areas encompassing $95 \%$ of foraging locations for birds from different islands overlapped extensively, but those encompassing $50 \%$ of locations were non-overlapping (numbered 1,2 and 3 for the western, central and eastern Azores respectively)

\section{Variation in travel speeds during trips}

Speeds of travel over intervals $\leq 2 \mathrm{~h}$ within trips (see 'Materials and methods') were significantly higher during the day (mean per trip $=16.8 \pm 6.6 \mathrm{~km} \mathrm{~h}^{-1}, \mathrm{n}=$ 100 trips $)$ than at night $\left(10.2 \pm 6.7 \mathrm{~km} \mathrm{~h}^{-1}, \mathrm{n}=100\right.$; paired $t$-test; $\left.t_{99}=8.7, \mathrm{p}<0.001\right)$. This difference was apparent during both STs $\left(14.7 \pm 5.8 \mathrm{~km} \mathrm{~h}^{-1}, \mathrm{n}=75\right.$ by day, $9.2 \pm 6.9 \mathrm{~km} \mathrm{~h}^{-1}, \mathrm{n}=75$ at night; paired $t_{74}=5.9$, $\mathrm{p}<0.001)$ and LTs $\left(23.2 \pm 4.5 \mathrm{~km} \mathrm{~h}^{-1}, \mathrm{n}=25\right.$ by day, $13.1 \pm 5.1 \mathrm{~km} \mathrm{~h}^{-1}, \mathrm{n}=25$ at night; paired $t_{24}=9.4, \mathrm{p}<$ 0.001). For LTs, we used the total distance travelled over the first and final $2 \mathrm{~d}$ of the trip to estimate average speed during the outward and return sections of the trip, respectively. Birds travelled out from the colony and returned at similar speeds $(23.8 \pm 8.0 \mathrm{~km}$ $\mathrm{h}^{-1}, \mathrm{n}=25$ and $25.7 \pm 8.0 \mathrm{~km} \mathrm{~h}^{-1}, \mathrm{n}=25$ respectively), about $50 \%$ faster than during the middle section of the trip (17.5 $\left.\pm 4.7 \mathrm{~km} \mathrm{~h}^{-1}, \mathrm{n}=25\right)$. Similarly, the straightline distance between locations at the beginning and end of each section comprised a much greater proportion of the total distance travelled during outward and return legs $(67.1 \pm 13.7 \%, \mathrm{n}=25$ and $74.3 \pm 13.5 \%, \mathrm{n}=$ 25 , respectively) than during the middle section of the trip $(29.4 \pm 17.0 \%, \mathrm{n}=25)$, indicating much less sinuous flight-paths on the outward and return legs.

\section{Food provisioning rates of chicks}

Over the period 10 to $60 \mathrm{~d}$ post-hatching, when food provisioning rate is independent of chick age (Ramos et al. 2003), each chick was fed on $59.3 \pm 9.7 \%$ of nights ( $\mathrm{n}=77$ chicks), with no difference in this proportion between islands (Table 2; 1-way ANOVA of arcsine-transformed data with a single mean value for each chick $F_{2,74}=2.6, \mathrm{p}=0.1$ ). Intervals between meals delivered to chicks ranged from 1 to $9 \mathrm{~d}$ (Fig. 6), with an average interval of $1.69 \pm 1.2 \mathrm{~d}$ ( $\mathrm{n}=77$ chicks $)$ and no difference in intervals between islands (Table 2; Kruskal-Wallis $\chi_{2}^{2}=1.69, \mathrm{p}=0.4$ ). When fed, chicks received $127.2 \pm 42.1 \mathrm{~g}$ of food overnight (Table 2) with no difference between islands in mean feed size per chick $\left(F_{2,74}=0.6, \mathrm{p}=0.5\right)$. Chicks at all 3 islands received significantly larger feeds when tagged parents returned from LTs (mean = $154.9 \pm$ $53.5 \mathrm{~g}, \mathrm{n}=28$ ) than from STs (mean $=113.5 \pm 62.1 \mathrm{~g}, \mathrm{n}=$ 152; GLMM; for difference between LTs and STs, $F_{1,144}=13.2, \mathrm{p}<0.001$; for difference between islands, $\left.F_{2,144}=0.9, \mathrm{p}=0.5\right)$. The overall food provisioning rate was $75.8 \pm 27.1 \mathrm{~g} \mathrm{night}^{-1}$ (Table 2 ) and the mean mass growth rate of chicks was $14.1 \pm 3.7 \mathrm{~g} \mathrm{~d}^{-1}$ (Table 2), with no difference between islands in either case $\left(F_{2,74}=0.9, \mathrm{p}=0.9\right.$ and $F_{2,74}=3.0, \mathrm{p}=0.1$, respectively $)$.

\section{DISCUSSION}

Cory's shearwaters breeding in the Azores employed dual-foraging to exploit feeding areas up to $1800 \mathrm{~km}$ from the nest (average range $=1107 \mathrm{~km}$; from data in

Table 2. Calonectris diomedea. Food provisioning and growth rates of chicks. Based on 14 chicks in the western Azores, 17 in the central Azores and 46 in the eastern Azores

\begin{tabular}{|c|c|c|c|c|c|c|c|c|c|c|}
\hline \multirow[t]{2}{*}{$\begin{array}{l}\text { Island } \\
\text { group }\end{array}$} & \multicolumn{2}{|c|}{$\begin{array}{c}\text { Proportion of } \\
\text { nights chick fed }\end{array}$} & \multicolumn{2}{|c|}{$\begin{array}{c}\text { Interval } \\
\text { between feeds (d) }\end{array}$} & \multicolumn{2}{|c|}{$\begin{array}{l}\text { Feed size } \\
\quad(g)\end{array}$} & \multicolumn{2}{|c|}{$\begin{array}{l}\text { Provisioning rate } \\
\qquad\left(\mathrm{g} \mathrm{night}^{-1}\right)\end{array}$} & \multicolumn{2}{|c|}{$\begin{array}{l}\text { Mass growth } \\
\text { rate }\left(\mathrm{g} \mathrm{d}^{-1}\right)\end{array}$} \\
\hline & Mean & $\mathrm{SD}$ & Mean & $\mathrm{SD}$ & Mean & $\mathrm{SD}$ & Mean & $\mathrm{SD}$ & Mean & $\mathrm{SD}$ \\
\hline Western & 0.61 & 0.10 & 1.62 & 1.01 & 115.9 & 28.3 & 72.8 & 24.1 & 14.2 & 3.7 \\
\hline Central & 0.63 & 0.11 & 1.64 & 1.17 & 121.0 & 29.7 & 77.7 & 22.3 & 15.9 & 3.3 \\
\hline Eastern & 0.58 & 0.10 & 1.74 & 1.27 & 130.5 & 47.5 & 75.8 & 25.9 & 13.4 & 3.7 \\
\hline
\end{tabular}




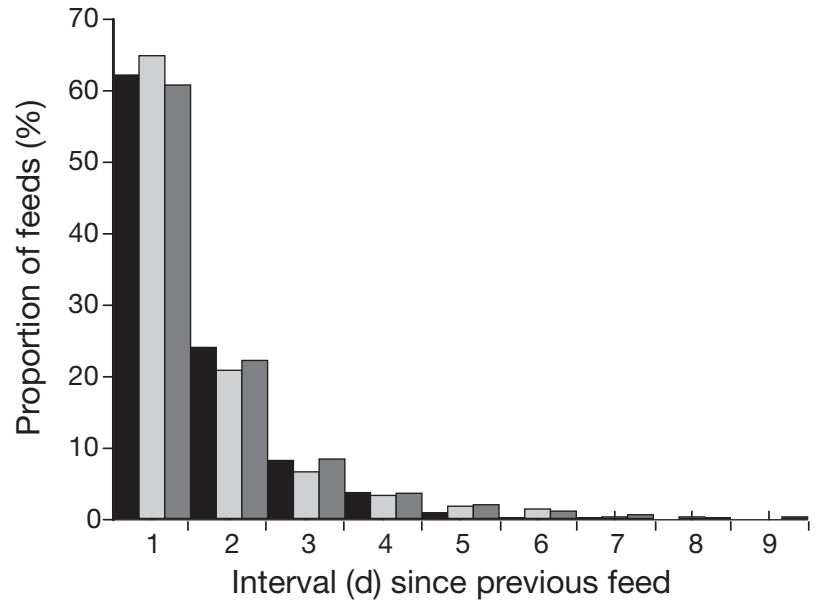

Fig. 6. Calonectris diomedea. Intervals between successive feeds for chicks at 3 islands in the Azores (black: western Azores; light grey: central Azores; dark grey: eastern Azores

Table 1). This supports the notion that dual-foraging among Procellariiformes to exploit sites at great distance from the nest is not confined to the Southern Ocean or to albatrosses in other oceanographic regions. Dual-foraging was not recorded, however, in Cory's shearwaters breeding in the Berlengas Islands off the west coast of Portugal or in most years studied in the Selvagens Islands, $1400 \mathrm{~km} \mathrm{SE}$ of the Azores in the North Atlantic Ocean (Hamer \& Hill 1993, Granadeiro et al. 1998a, Hamer et al. 1999). Thus, foraging strategies of individual species of Procellariiformes may vary both spatially and temporally, presumably in relation to variation in the distribution and abundance of pelagic prey resources around different breeding sites (Baduini \& Hyrenbach 2003, Congdon et al. 2005). The consistent presence of dual-foraging in this study suggests that prey availability close to land may be lower on average in the Azores than at other North Atlantic colonies of this species.

STs from all 3 island groups in the Azores tended to remain close to the MAR, with only trips from the western Azores heading away from the ridge across deep water, the longest short trip extending to a small cluster of seamounts at the eastern extremity of the Milne seamount chain west of the MAR (Figs. 3 \& 4). In contrast to studies in other oceanographic regions (e.g. Catard et al. 2000), STs in the Azores were widely spaced and not restricted to a narrow range of locations, presumably indicating a more even distribution of prey resources around breeding colonies in the Azores. There was a clear distinction between STs and LTs in the central and eastern Azores, but less so in the western Azores, where the destination of the longest ST was beyond the core foraging area during LTs (Figs. 3 \& 5).

Core foraging areas of LTs from the central and western Azores were over the MAR north of the colony and over the western flank of the MAR northwest of the colony, respectively (Figs. 4 \& 5). The MAR north of the Azores is a likely area of enhanced productivity resulting from cold water upwelling and eddies, particularly in the vicinity of seamounts (Haney et al. 1995, Haury et al. 2000, Morato et al. 2008a,b), which have their highest density between the Azores and the Charlie Gibbs Fracture Zone at $52^{\circ} \mathrm{N}$ (Epp \& Smoot 1989, Gubbay 2003). The density of seamounts along the MAR declines markedly north of this zone, and this was the most northerly location of foraging birds during the study (Fig. 4). In addition, at least 1 LT from all 3 island groups extended as far as Flemish Cap east of Newfoundland (Fig. 4), which is an offshore seamount in a region of high productivity associated with the mixing of cold waters of the Labrador Current with warm sub-tropical waters. Thus, as with other species in different oceanographic regions (Baduini \& Hyrenbach 2003), LTs of Cory's shearwaters in the Azores appeared to give birds access to regions of enhanced productivity at long distances from the nest. Birds from the eastern Azores had more variable foraging paths, but LTs of 2 birds included concentrated foraging activity in a region of variable depth at the edge of deep water $(>3000 \mathrm{~m})$ to the north and west of the Charcot seamounts NW of Portugal and SW of Ireland (Fig. 4), which may also be a region of enhanced productivity.

Despite marked differences between islands in trip durations, foraging ranges and total distances travelled, the behaviour of birds during foraging trips was very similar in each case. Birds travelled faster and more directly during LTs than during STs but there was no difference between islands in the average speed of travel over STs or LTs and the relationship between distance to destination and total distance travelled was also very similar in each case, as was the proportion of the total foraging area (95\% FKD) that comprised the core foraging area (Table 1). These data strongly suggest that birds did not alter their overall search strategy or sinuosity of foraging paths (i.e. the extent of deviation from a straight-line course) between islands in relation to trip duration or foraging range. There was no difference between sexes in behaviour at sea but birds travelled more slowly by night than by day, as also found in some other species of Procellariiformes (e.g. Hedd et al. 2001), probably resulting from birds spending a greater proportion of time resting on the sea surface at night. Average rates of travel to and from distant foraging sites $\left(24 \mathrm{~km} \mathrm{~h}^{-1}\right.$ and $26 \mathrm{~km} \mathrm{~h}^{-1}$, respectively) were similar to those recorded in white-chinned petrels Procellaria aequinoctalis (Catard et al. 2000) and close to the estimated flight speed for Cory's shearwaters (30 $\mathrm{km} \mathrm{h}^{-1}$; Dallantonia et al. 1995), suggesting that birds spent most of their time in flight along a more or less direct path when commuting, as 
also suggested by the low sinuosity of flight-paths during outward and return legs (see 'Results: Variation in travel speeds during trips').

LTs lasting up to $20 \mathrm{~d}$ could result in chicks being unfed for long periods if both parents departed on LTs simultane<ously, but this problem could be reduced if the 2 parents co-ordinated their provisioning, as found in wedge-tailed shearwaters (Congdon et al. 2005). In our study, assuming the 2 parents returned independently of each other, the expected percentage of chicks fed each night (from a binomial distribution based on each parent returning on $37 \%$ of nights) would be $60 \%\left(1-(1-0.37)^{2}\right)$, which was very close to the percentage observed (59\%) and corresponds with previous data from the Azores (50 to $70 \%$ of chicks fed per night; Klomp \& Furness 1992, Ramos et al. 2003). These data strongly suggest that the 2 parents did not co-ordinate their activity to reduce the number of nights when chicks were unfed. As a result, the maximum interval between feeds in the Azores (9 nights; Fig. 6) was much longer than previously recorded in the absence of dual-foraging (4 nights; Hamer \& Hill 1993, Granadeiro et al. 1998a, Hamer et al. 1999). In common with other Procellariiformes, Cory's shearwaters accumulate large quantities of body fat as nestlings (Hamer \& Hill 1993) and maximum intervals between feeds were previously considered too short to explain the sizes of fat stores accumulated. Chicks may, however, require such large stores to survive longer intervals resulting from a dual-foraging strategy among parents, as previously suggested for short-tailed shearwaters Puffinus tenuirostris in the Southern Ocean (Schultz \& Klomp 2000).

Despite long intervals between feeds, the overall provisioning rate of chicks in the Azores $\left(76 \mathrm{~g} \mathrm{night}^{-1}\right.$; Table 2) was very similar to that recorded elsewhere in the absence of dual-foraging (e.g. mean of $3 \mathrm{yr}$ in the Selvagens Islands $=74 \mathrm{~g} \mathrm{night}^{-1}$; data from Table 1 in Hamer et al. 1999). Mass growth rates of chicks in this study (14 $\mathrm{g} \mathrm{day}^{-1}$ on average) were also similar to those recorded previously in the Azores and elsewhere for chicks of similar age (Hamer \& Hill 1993, Ramos et al. 2003) The similarity in provisioning and growth rates of chicks under unimodal and dual foraging was probably because the mean mass of food delivered when chicks were fed was higher in the Azores (127 g; Table 2) than elsewhere (96 g; Hamer et al. 1999), reflecting larger meals delivered by parents after LTs (see 'Results: Food provisioning rates of chicks'; Granadeiro et al. 1998a, Weimerskirch \& Cherel 1998). Despite shorter LTs in the western Azores than elsewhere (Table 1), there was no difference between islands in either the proportion of nights each adult returned or the proportion of nights each chick was fed, because shorter LTs in the western Azores were accompanied by longer STs (Table 1).
Cory's shearwaters are opportunistic predators (Granadeiro et al. 1998b) and concern has been expressed over incidental mortality of adults in longline fisheries in the Mediterranean and Macaronesia (Cooper et al. 2003, Gonzáles-Solís et al. 2007). Our data suggest that breeding adults from the Azores could potentially be affected by interactions with fisheries over a much larger area of ocean than previously recognized, paralleling recent findings for the overwintering and migration periods (GonzálesSolís et al. 2007).

Acknowledgements. We are grateful to all who gave us valuable assistance in the field, particularly Mário Laranjo, Anaid D. Palacios, Eva Alamo, Nuno Lima, Marco Dutra, Luís Aguiar, Pedro Domingos, Ricardo Guerreiro, Deborah and Sheila Russel, Cláudia Oliveira and Jeremy Sabel. Permits were issued by the Azores Secretary of Environment and the Sea (SRAM)/ Regional Directorat of Environment (DRA). This research was supported by European Commission projects OGAMP/InterregIIIb/MAC/4.2/A2/2004 and MARMAC/InterRegIIIb-03/ MAC4.2/A1 and MARMACII/InterRegIIIb-05/MAC/4.2/A4/ 2007), SRAM and IMAR (Institute of Marine Research). IMARDOP/UAz is Research and Development Unit \#531 and Associated Laboratory \#9 funded by the Portuguese Foundation for Science and Technology (FCT) through pluri-annual and programmatic funding schemes (FEDER, POCI2001, FSE) and by the Azores Directorat for Science and Technology (DRCT).

\section{LITERATURE CITED}

Baduini CL (2002) Parental provisioning patterns of wedgetailed shearwater chicks and their relation to chick body condition. Condor 104:823-831

Baduini CL, Hyrenbach D (2003) Biogeography of procellariiform foraging strategies: does ocean productivity influence provisioning? Mar Ornithol 31:101-112

> Beisiegel BM, Mantovani W (2006) Habitat use, home range and foraging preferences of the coati Nasua nasua in a pluvial tropical Atlantic forest area. J Zool (Lond) 269: $77-87$

Catard A, Weimerskirch H, Cherel Y (2000) Exploitation of distant Antarctic waters and close shelf-break waters by white-chinned petrels rearing chicks. Mar Ecol Prog Ser 194:249-261

Congdon BC, Krockenberger AK, Smithers BV (2005) Dualforaging and co-ordinated provisioning in a tropical Procellariiform, the wedge-tailed shearwater. Mar Ecol Prog Ser 301:293-301

Cooper J, Baccetti N, Belda EJ, Borg JJ, Oro D, Papaconstantinou C, Sanchez A (2003) Seabird mortality from longline fishing in the Mediterranean Sea and Macaronesian waters: a review and a way forward. Sci Mar 67 (Suppl 2):57-64

Dall'Antonia L, Dallantonia P, Benvenuti S, Ioale P, Massa B, Bonadonna F (1995) The homing behaviour of Cory's shearwaters (Calonectris diomedea) studied by means of a direction recorder. J Exp Biol 198:359-362

> Epp D, Smoot NC (1989) Distribution of seamounts in the North Atlantic. Nature 337:254-257

> Fernandez P, Anderson DJ, Sievert PR, Huyvaert KP (2001) Foraging destinations of three low-latitude albatross (Phoebastria) species. J Zool (Lond) 254:391-404

Fridolfsson AK, Ellegren TH (1999) A simple and universal 
method for molecular sexing of non-ratite birds. J Avian Biol 30:116-121

González-Solís J, Croxall JP, Oro D, Ruiz X (2007) Transequatorial migration and mixing in the wintering areas of a pelagic seabird. Front Ecol Environ 5:297-301

Granadeiro JP (1991) The breeding biology of Cory's shearwater Calonectris diomedea on Berlenga Island, Portugal. Seabird 13:30-39

> Granadeiro JP, Nunes M, Silva MC, Furness RW (1998a) Flexible foraging strategy of Cory's shearwater, Calonectris diomedea, during the chick-rearing period. Anim Behav 56:1169-1176

Granadeiro JP, Monteiro LR, Furness RW (1998b) Diet and feeding ecology of Cory's shearwater Calonectris diomedea in the Azores, north-east Atlantic. Mar Ecol Prog Ser 166:267-276

Gray CM, Hamer KC (2001) Food provisioning behaviour of male and female Manx shearwaters Puffinus puffinus. Anim Behav 62:117-121

Gubbay S (2003) Seamounts of the north-east Atlantic. OASIS, Hamburg and WWF Germany, Frankfurt am Main

> Hamer KC, Hill JK (1993) Variation and regulation of meal size and feeding frequency in Cory's shearwater Calonectris diomedea. J Anim Ecol 62:441-450

Hamer KC, Hill JK (1997) Nestling obesity and variability of food delivery in Manx shearwaters, Puffinus puffinus. Funct Ecol 11:489-497

Hamer KC, Hill JK, Scott I (1999) Chick provisioning and parental attendance in Cory's shearwaters: implications for nestling obesity. J Avian Biol 30:309-315

Hamer KC, Quillfeldt P, Masello JF, Fletcher KL (2006) Sex differences in provisioning rules: responses of Manx shearwaters to supplementary chick feeding. Behav Ecol $17: 132-137$

> Hamer KC, Humphreys EM, Garthe S, Hennicke J and others (2007) Annual variation in diets, feeding locations and foraging behaviour of gannets in the North Sea: flexibility, consistency and constraint. Mar Ecol Prog Ser 338:295-305

> Haney JC, Haury LR, Mullineaux LS, Fey CL (1995) Sea-bird aggregation at a deep North Pacific seamount. Mar Biol 123:1-9

Haury LR, Fey C, Newland C, Genin A (2000) Zooplankton distribution around four eastern North Pacific seamounts. Prog Oceanogr 45:69-105

Hedd A, Gales R (2005) Breeding and overwintering ecology of shy albatrosses in southern Australia: year-round patterns of colony attendance and foraging-trip durations. Condor 107:375-387

Hedd A, Gales R, Brothers N (2001) Foraging strategies of shy albatross Thalasarche cauta breeding at Albatross Island, Tasmania, Australia. Mar Ecol Prog Ser 224:267-282

> Hyrenbach KD, Fernandez P, Anderson DJ (2002) Oceanic habitats of two sympatric North Pacific albatrosses during the breeding season. Mar Ecol Prog Ser 233:283-301

Igual JM, Forero MG, Tavecchia G, Gonzalez-Solis J and others (2005) Short-term effects of data-loggers on Cory's shearwater (Calonectris diomedea). Mar Biol 146:619-624

Iversen SA, Esler D (2006) Site fidelity and the demographic implications of winter movements by a migratory bird, the harlequin duck Histrionicus histrionicus. J Avian Biol 37: 219-228

Klomp NI, Furness RW (1992) Patterns of chick feeding in Cory's shearwaters and the associations with ambient light. Colon Waterbirds 15:95-102

Klomp NI, Schultz MA (2000) Short-tailed shearwaters breeding in Australia forage in Antarctic waters. Mar Ecol Prog

Editorial responsibility: Otto Kinne,

Oldendorf/Luhe, Germany
Ser 194:307-310

> Monteiro LR, Ramos JA, Furness RW (1996) Past and present status and conservation of the seabirds breeding in the Azores archipelago. Biol Conserv 78:319-328

Morato $T$, Machete M, Kitchingman A, Tempera F, Lai S, Menezes G, Pitcher TJ, Santos RS (2008a) Abundance and distribution of seamounts in the Azores. Mar Ecol Prog Ser $357: 17-21$

Morato T, Varkey DA, Dâmaso C, Machete M, Santos M, Prieto R, Santos RS, Pitcher TJ (2008b) Evidence of a seamount effect on aggregating visitors. Mar Ecol Prog Ser 357:23-32

Mougin JL, Jouanin C (1997) Prospection alimentaire du puffin cendré Calonectris diomedea borealis de Selvagem Grande $\left(30^{\circ} 9^{\prime} \mathrm{N}, 15^{\circ} 52^{\prime} \mathrm{W}\right)$ pendant l'incubation, par télémétrie satellitaire. CR Acad Sci Paris 320:825-831

Nøttestad L, Olsen E (2005) The mid-Atlantic ridge is teeming with life. Northern Fisheries, Newsletter from the Nordic Working Group on Fisheries Research 25:1-3 (available at: www.norden.org/nordfiskeri/sk/)

Phillips RA, Xavier JC, Croxall JP (2003) Effects of satellite transmitters on albatrosses and petrels. Auk 120: 1082-1090

> Phillips RA, Silk JRD, Croxall JP (2005) Foraging and provisioning strategies of the light-mantled sooty albatross at South Georgia: competition and co-existence with sympatric pelagic predators. Mar Ecol Prog Ser 285:259-270

Ramos JA, Moniz Z, Sola E, Monteiro LR (2003) Reproductive measures and chick provisioning of Cory's shearwater Calonectris diomedea borealis in the Azores. Bird Study 50:47-54

Ropert-Coudert Y, Wilson RP, Daunt F, Kato A (2004) Patterns of energy aquisition by a central place forager: benefits of alternating short and long foraging trips. Behav Ecol 15: $824-830$

Schultz MA, Klomp NI (2000) Does the foraging strategy of short-tailed shearwaters cause obesity in their chicks? J Avian Biol 31:287-294

Stahl JC, Sagar PM (2000) Foraging strategies of southern Buller's albatrosses Diomedea b. bulleri breeding on the Snares, New Zealand. J R Soc N Z 30:299-318

Terauds A, Gales R (2006) Provisioning strategies and growth patterns of light-manted sooty albatrosses Phoebetria palpebrata on Macquarie Island. Polar Biol 29:917-926

Waugh SM, Weimerskirch H, Cherel Y, Shankar U, Prince PA, Sagar PM (1999) Exploitation of the marine environment by two sympatric albatrosses in the Pacific Southern Ocean. Mar Ecol Prog Ser 177:243-254

Weimerskirch H (2007) Are seabirds foraging for unpredictable resources? Deep-Sea Res II 54:211-223

Weimerskirch H, Cherel Y (1998) Feeding ecology of shorttailed shearwaters: breeding in Tasmania and foraging in the Antarctic? Mar Ecol Prog Ser 167:261-274

> Weimerskirch H, Chastel O, Ackermann L, Chaurand T, Cuenotchaillet F, Hindermeyer X, Judas J (1994) Alternate long and short foraging trips in pelagic seabird parents. Anim Behav 47:472-476

> Weimerskirch H, Chastel O, Cherel Y, Henden JA, Tveraa T (2001) Nest attendance and foraging movements of northern fulmars rearing chicks at Bjørnøya Barents Sea. Polar Biol 24:83-88

Wilson RP, Scolaro JA, Grémillet D, Kierspel MAM and others (2005) How do magellanic penguins cope with variability in their access to prey? Ecol Monogr 75:379-401

- Worton BJ (1989) Kernel method for estimating the utilization distribution in home range studies. Ecology 70:164-168 